\title{
Role of a neuronal small non-messenger RNA: behavioural alterations in BC1 RNA-deleted mice
}

\author{
L. Lewejohann ${ }^{\text {a }}$, , B.V. Skryabin ${ }^{\text {b }}$, N. Sachser ${ }^{\text {a }}$, C. Prehn ${ }^{\text {c}}$, P. Heiduschka ${ }^{d}$, S. Thanos ${ }^{d}$, \\ U. Jordan ${ }^{b}$, G. Dell'Omo ${ }^{\text {e }}$, A.L. Vyssotski ${ }^{\mathrm{e}}$, M.G. Pleskacheva ${ }^{\mathrm{f}}$, \\ H.-P. Lipp ${ }^{\mathrm{e}}$, H. Tiedge ${ }^{\mathrm{g}}$, J. Brosius ${ }^{\text {b }}$, H. Prior ${ }^{\mathrm{c}}, 1$ \\ ${ }^{a}$ Department of Behavioural Biology, University of Münster, D-48149 Münster, Germany \\ ${ }^{\mathrm{b}}$ Institute of Experimental Pathology, University of Münster, D-48149 Münster, Germany \\ c Institute for Cognitive Neuroscience and Biopsychology, University of Bochum, D-44780 Bochum, Germany \\ ${ }^{\mathrm{d}}$ Department of Experimental Ophthalmology, University of Münster, D-48149 Münster, Germany \\ ${ }^{\mathrm{e}}$ Division of Neuroanatomy and Behaviour, Neuroscience Centre, Institute of Anatomy, University of Zürich, Zürich, Switzerland \\ ${ }^{\mathrm{f}}$ Laboratory of Physiology and Genetics of Behaviour, Faculty of Biology, Moscow State University, Moscow, Russia \\ g Department of Physiology and Pharmacology, State University of New York, Health Science Center at Brooklyn, Brooklyn, NY 11203, USA
}

Received 25 November 2003; received in revised form 18 February 2004; accepted 18 February 2004

Available online 1 April 2004

\begin{abstract}
BC1 RNA is a small non-messenger RNA common in dendritic microdomains of neurons in rodents. In order to investigate its possible role in learning and behaviour, we compared controls and knockout mice from three independent founder lines established from separate embryonic stem cells. Mutant mice were healthy with normal brain morphology and appeared to have no neurological deficits. A series of tests for exploration and spatial memory was carried out in three different laboratories. The tests were chosen as to ensure that different aspects of spatial memory and exploration could be separated and that possible effects of confounding variables could be minimised. Exploration was studied in a barrier test, in an open-field test, and in an elevated plus-maze test. Spatial memory was investigated in a Barnes maze and in a Morris water maze (memory for a single location), in a multiple T-maze and in a complex alley maze (route learning), and in a radial maze (working memory). In addition to these laboratory tasks, exploratory behaviour and spatial memory were assessed under semi-naturalistic conditions in a large outdoor pen. The combined results indicate that BC1 RNA-deficient animals show behavioural changes best interpreted in terms of reduced exploration and increased anxiety. In contrast, spatial memory was not affected. In the outdoor pen, the survival rates of BC1-depleted mice were lower than in controls. Thus, we conclude that the neuron-specific non-messenger BC1 RNA contributes to the aptive modulation of behaviour.
\end{abstract}

(C) 2004 Elsevier B.V. All rights reserved.

Keywords: BC1 RNA; Knockout mouse; Exploration; Learning and memory; Outdoor enclosure

\section{Introduction}

Genetically closely related animal species can differ quite drastically in their behaviour. In fact, differences in behaviour including sexual selection can be one of the driving forces of speciation [31]. Pertinent behavioural changes are not necessarily induced by recruitment of numerous addi-

\footnotetext{
* Corresponding author. Tel.: +49-251-83-24783; fax: +49-251-83-23896.

E-mail addresses: 1johann@phenotyping.com (L. Lewejohann), helmut.prior@ruhr-uni-bochum.de (H. Prior).

1 Tel.: +49-234-322-8213; fax: +49-234-321-4377.
}

tional genes as relatively few novel genes appear to have arisen in mammalian orders after they diverged from a common ancestor about 80-100 million years ago [9]. Generation of novel alleles by point mutations, novel protein domains by alternative splicing, or differential expression of existing genes might suffice to promote differential animal behaviour. A small untranslated RNA, BC1 RNA, is about 60-110 million years old and arose in a common ancestor of all rodents by a process termed retroposition [8]. The RNA gene product is located in cell bodies and dendritic processes of a subset of neurons in particular in neocortex, hippocampus, amygdala, ventral lateral geniculate nucleus, supraoptic nucleus, nucleus tractus solitarius and trigeminal 
nucleus [45]. It is a candidate gene responsible for functions that may be underlying novel behavioural patterns in a mammalian order. BC1 RNA has been suggested to operate in the regulation of dendritic protein synthesis, or alternatively as a mediator of dendritic mRNA transport [43-45,48]. In an initial analysis, however, the latter notion was shown to be unlikely [41]. Initially, due to the origin of BC1 RNA by retropositional duplication of a transfer RNA (tRNA ${ }^{\mathrm{Ala}}$ ) in conjunction with its unique expression pattern in the rodent nervous system $[15,45]$, a role in regulation of post-synaptic protein synthesis had been suggested $[10,45]$. The biochemical role of BC1 RNA in translation recently received experimental support $[21,48]$. Due to the evolutionarily young age of BC1 RNA we anticipated that its elimination would not affect basic memory performance or simple behavioural routines. Consequently, we wished to examine its possible role in complex adaptive behaviours.

For example, in rodents, genetic variability of spatial behaviour between and within species is a well-documented example of aptive (aptation = adaptation and/or exaptation; see [18]) specialisation of the brain. Vole species with different home ranges and habitats vary with respect to hippocampal size and microstructure. This correlates with spatial behaviour in the field and in the laboratory $[19,36]$. In natural mouse populations similar aptations occur [5]. Spatial behaviour is based on an integration of different brain mechanisms. Firstly, differences in spatial memory enable individuals to cope with habitats of different size and variability. Secondly, seemingly undirected movements in space, often referred to as exploration, are regulated by brain mechanisms associated with fear and/or detection of novelty. This permits the animal to adjust movements in space according to the availability of resources, access to reproductive partners, and presence of predators.

Our aim was to examine two essential aspects of spatial behaviour, namely spatial memory and exploration. In order to exclude that possible differences were dependent on the particular tests performed [20], we used several different test systems to examine spatial memory and exploration. In addition, experimental findings in one laboratory were verified in others, intentionally using slightly different experimental setups in order to avoid some inherent risks of standardisation [52]. As a matter of fact, behaviour always reflects the interaction of genetic predisposition and environmental influence. Barren housing conditions may constrain behaviour and brain development, resulting in behavioural abnormalities and aberrant brain functions [53]. In contrast, it is known that introducing additional structures like hiding places, climbing frames, etc. into the cages ("environmental enrichment") can have an impact on performance of mice in established behavioural tests (for a review see [34]). As a systematic variation of environmental influences, mice reared and tested in one of the labs were housed in enriched cages.

To reduce confounding effects of genetic background inbreeding or effects of random mutations on embryonic stem cells (ES), all tests were carried out with three hybrid mouse lines (129SV $\times$ C57BL/6) established from independent ES clones, all lacking the BC1 RNA-gene. Finally, laboratory tests were complemented by investigations under semi-naturalistic conditions in a large outdoor pen. This strengthens our analysis by providing data on spatial behaviour in a controlled but naturally complex system. Also, survival rates as an ultimate test for the utility of a gene could be obtained.

\section{Materials and methods}

\subsection{Animals}

The subjects were male and female BC1-deficient mice. A previous paper describes in detail how the three lines were established [41]. Gross morphological changes in BC1-deficient mice were excluded [41]. Mice of all three lines and controls were bred at the central animal facility of the University Clinics, Münster, in a temperature-controlled $\left(21^{\circ} \mathrm{C}\right)$ room with a $12: 12 \mathrm{~h}$ light-dark cycle and were housed under non-enriched standard conditions. Pups were weaned at 19-23 days after birth and females were kept separately from males. Mice were housed in standard $(27 \mathrm{~cm}$ (length) $\times 21 \mathrm{~cm}$ (width) $\times 15 \mathrm{~cm}$ (height) $)$ or $(42 \mathrm{~cm}$ (length) $\times 27 \mathrm{~cm}$ (width) $\times 15 \mathrm{~cm}$ (height) $)$ cages, for up to three or up to seven littermates, respectively. General health checks were performed for all lines of wild-type and knock-out mice to ensure that behavioural findings were not the result of deteriorating physical conditions of the animals. All procedures and protocols met the guidelines for animal care and animal experiments in accordance with national and European (86/609/EEC) legislation.

At Bochum University (referred to as LAB1) subjects, which had been transferred from Münster, were housed in a temperature-controlled $\left(21 \pm 1{ }^{\circ} \mathrm{C}\right)$ colony room with a $12: 12 \mathrm{~h}$ light-dark cycle in standard laboratory cages $(27 \mathrm{~cm}$ (length) $\times 21 \mathrm{~cm}$ (width) $\times 15 \mathrm{~cm}$ (height)), two sex-mates per cage. Subjects were handled for several days before behavioural tests or maze learning started. In the Department of Behavioural Biology at the University of Münster (referred to as LAB2) locally bred mice were housed in the same temperature and lighting conditions as in Bochum and also handled routinely. Beginning with the second litter of each breeding pair, pups (3 days old) were culled to four sex-matched littermates. Pups were weaned at day 21 and transferred to standard laboratory cages (4 per cage; cage size: $42 \mathrm{~cm}$ (length) $\times 27 \mathrm{~cm}$ (width) $\times 15 \mathrm{~cm}$ (height) $)$ enriched with a wooden climbing frame and a plastic inset with several holes [37] (for a photo see [29]). In addition, 160 mice reared in non-enriched cages (original colony) were transferred to LAB2 to assess the effects of different environmental experiences on performance in the barrier test (see below). For tests in semi-naturalistic outdoor settings a total of 96 mice (two BC1-deficient lines and wild-type) 
reared in the original colony (Münster) were shipped to Moscow State University and thereafter to a field station in Western Russia (both locations referred to as LAB3). At the onset of the field tests the mice were about 3 months old.

\subsubsection{General health check}

Health and neurological status were assessed at LAB2 using a 10-min protocol including tests as described in standard check lists such as SHIRPA [40] and the Fox battery [17]. Animals were inspected for physical appearance, and underwent neurological testing including acoustic startle, visual placing, grip strength and reflex functions.

\subsubsection{Measurements of flash visual evoked potentials (FVEP)}

Animals were anaesthetised with $7 \%$ chloral hydrate (0.42 $\mu \mathrm{g} / \mathrm{g}$ body weight, i.p.). Stainless, self-tapping screws (1/8 in. length, 0.044 in. diameter, Small Parts, Inc., Miami Lakes, FL) were used as recording electrodes. Two holes were drilled into the skulls of the animals above the left and right visual cortex, respectively, approximately $1.5-2 \mathrm{~mm}$ lateral to the midline and $2-3 \mathrm{~mm}$ anterior to lambda. The screws were inserted into the skull at a depth of $2 \mathrm{~mm}$, penetrating the surface of the visual cortex. The electrodes were connected directly to a shielded co-axial cable leading to an amplifier. The silver wire reference electrode was placed subcutaneously above the anterior part of the skull. The optical stimulus was a flash of light, produced by a fast rechargeable photographic flash triggered by computer (Unomat, Reutlingen, Germany). Signals in the frequency range between 0.1 and $500 \mathrm{~Hz}$ were amplified 1000-fold with an ISO-DAM8 multi-channel amplifier (World Precision Instruments, Sarasota, FL). The VEP was recorded directly after the flash for $200 \mathrm{~ms}$ at a sampling rate of $2000 \mathrm{~Hz}$. VEPs from 10 flashes, with time intervals of $60 \mathrm{~s}$ between individual flashes, were averaged by a computer coupled to the amplifier, using the MP 100 data-acquisition system (BIOPAC Systems, Inc., Santa Barbara, CA). Both the latencies after flash onset and amplitudes of the averaged VEPs of each group were compared.

\subsubsection{Daily activity rhythm}

The animals' activity over the course of the day was assessed in home cages in the laboratory and in an seminaturalistic outdoor enclosure (for details see below). While the first is likely to mainly reflect the spontaneous locomotor activity, the latter probably reflects the daily pattern of exploration of the environment. Activity rhythm in the home-cage was assessed at LAB2. Forty mice were housed individually 1 week prior to the observation period. Activity was recorded for 5 consecutive days by means of a video camera suspended in front of the cages observing four cages at a time. Movements were assessed by a video image analysing system (http://www.phenotyping.com/digital. html) with a sampling frequency of 5 images/s [25].

\subsection{Locomotion, exploration and anxiety}

We used three tests of exploratory behaviour with increasing loads of presumed fear: the barrier test, the open-field test, and the elevated plus-maze test. Since male and female mice can show different responses in some of the behavioural tests used in this study $[37,46]$, sex-specific differences were taken into account by using males and females on several of the tests. Although there were differences between males and females on some occasions, no consistent pattern of sex differences emerged. Therefore, data were combined.

\subsubsection{Barrier test}

Spontaneous exploratory behaviour was measured at LAB2 by means of the barrier test [37]. A standard cage $(27 \mathrm{~cm} \times 21 \mathrm{~cm} \times 15 \mathrm{~cm})$ was divided into two equal compartments by a $3 \mathrm{~cm}$ high, Plexiglas barrier. At the beginning of a test, mice were placed in one of the compartments according to a pseudo-random schedule. The latency was measured either as the time to climb over the barrier into the other compartment or a maximum time of 5 min elapsed without climbing over the barrier. Due to the similarity of the test apparatus to the home-cage, the barrier test is supposed to be the least fear-inducing of the tests. The apparatus was thoroughly cleaned after each trial by wiping the surfaces with ethanol $(70 \%)$. The same measures were taken for all subsequent tests (except the water maze).

\subsubsection{Open-field}

In the open-field test [47] mice had the opportunity to explore a square arena for a fixed amount of time. Locomotor activity and the ratio between exploration and fear of open space, as measured by the time spent near the walls or in the centre of the arena, were assessed. At LAB1 and LAB2 slightly different setups were used. In LAB1 the open-field was a dimly lit $(15 \mathrm{~lx}) 80 \mathrm{~cm} \times 80 \mathrm{~cm}$ square arena with walls $40 \mathrm{~cm}$ high, marked off in $20 \mathrm{~cm} \times 20 \mathrm{~cm}$ fields. Thus, 12 of the fields were adjacent to walls and 4 were in the centre. Each mouse was given one videotaped test session of five min, during which the number of entries into peripheral and central fields was scored. Based on the number of central and peripheral fields entered, the overall activity and the proneness to thigmotaxis (preference for sheltered areas such as walls or corners) versus central exploration were assessed. In LAB2 the open-field arena was the same size as that in LAB1, but more brightly illuminated (75 lx) and was not divided into fields. Instead, an automated tracking system and software (http://www.phenotyping.com/digital.html) was used to measure locomotor behaviour. Mice were videotaped for $10 \mathrm{~min}$, during which path length, velocity, stops and thigmotaxis from $x$-and $y$-coordinates was sampled at $5 \mathrm{~Hz}$.

\subsubsection{Elevated plus-maze}

Anxiety-related behaviour was measured at LAB1 and LAB2 by means of the elevated plus-maze $[28,35]$ on which 
mice had the choice to move into opposing arms, which were either shielded or open. Preference for open arms is thought to reflect exploration and preference for shielded arms is thought to indicate anxiety. In LAB1 the maze was elevated $50 \mathrm{~cm}$ above the floor and had arms $50 \mathrm{~cm}$ long and $10 \mathrm{~cm}$ wide. The maze was dimly lit (15lx) by a bulb suspended exactly above the centre of the maze to avoid shadows. At the beginning of a trial, mice were put into the centre of the maze randomly facing one of the arms. Each entry into an open or shielded arm was counted and the time animals spent in either type of arm was measured for $5 \mathrm{~min}$. Again, a slightly different setup was used in LAB2 $(5 \mathrm{~cm} \times 30 \mathrm{~cm}$ arms, elevated $50 \mathrm{~cm}$ above floor level, lit at $75 \mathrm{~lx}$ ), and each mouse was given one test session of $10 \mathrm{~min}$.

\subsection{Spatial memory in mazes}

Five tests for spatial memory were performed. Spatial memory for a single location was assessed in the Barnes maze and in the Morris water maze. Route learning was evaluated in an elevated multiple T-maze and a complex alley maze, and spatial working memory for feeding places was investigated in an 8 -arm radial maze. It is known that the error scores in tests for spatial memory can be influenced by factors not due to memory, e.g. by emotionality. By using tests with similar demands on the central aspect of spatial memory, but with different other requirements (running versus swimming; elevated maze versus enclosed maze), we ensured that effects on spatial memory could be separated from other effects.

\subsubsection{Barnes maze (LAB1)}

The cognitive demands of the Barnes maze task [4] are thought to be similar to those of the standard (non-cued) test in the Morris water maze [32], see below. During Barnes maze learning, mice had to learn the position of one of 12 symmetrically arranged holes on a circular platform with an $88 \mathrm{~cm}$ diameter. The circular holes were $4 \mathrm{~cm}$ wide and $4 \mathrm{~cm}$ from the brim. Below the platform, under one of the holes (the goal), was placed a box filled with the same wood shavings as the home cages and some food. Below the other holes, the space between the platform and the floor of the room was empty. The mice were confined for $15 \mathrm{~s}$ in a circular plastic cylinder in the centre of the maze until a trial was initiated by lifting the cylinder. Trials were controlled and recorded by means of a video system. The surroundings of the maze were brightly lit and landmarks on the walls of the room served as distal cues. Animals were given 12 trials on 6 consecutive days. In addition to cleaning, the maze was rotated around its central axis after each trial in order to control for possibly remaining odour cues.

\subsubsection{Water maze learning (LAB3)}

Mice were tested at Moscow State University for Morris maze navigation according to a standardised procedure described in detail elsewhere [27,51]. Briefly, the maze con- sisted of a circular white pool of $150 \mathrm{~cm}$ diameter, filled with water $\left(24-26^{\circ} \mathrm{C}\right)$ and made opaque by addition of milk. Distant visual cues for navigation were provided on the room walls. A wire mesh platform $(14 \mathrm{~cm} \times 14 \mathrm{~cm})$ was placed $0.5 \mathrm{~cm}$ below the water surface in the middle of one of the four pool quadrants. Mice were divided in four groups, each with a different platform position. They were placed in the pool using a plastic basket in order to minimise detection of external cues before being placed in the water. They were allowed a maximal time of $120 \mathrm{~s}$ to find the platform from which they were rescued after $5 \mathrm{~s}$. The schedule included 6 trials per day (30-40 min inter-trial interval) for 5 days. During the first 3 days (18 trials) the platform was kept in the same position (acquisition phase); during the remaining 2 days the platform was placed in the opposite pool quadrant to assess reversal learning (reversal phase). The first trial after platform relocation on day 4 served as a probe trial for spatial memory. Data were analysed using the proprietary software WINTRACK [50]. The following variables were extracted off-line: swim path length, escape time, percent of trials with failures ( 2 min without finding the platform), time spent near the wall (a zone $22.5 \mathrm{~cm}$ wide along the rim, corresponding to $50 \%$ of the water surface), and actual swim speed (measured only when the mice were actually moving). Spatial retention during the probe trial was defined by the time spent in the quadrant where the platform was previously located (old quadrant).

\subsubsection{Multiple T-maze (LAB1)}

On the multiple T-maze [38], mice had to learn a complex route, which was stable from trial to trial and, thus, required spatial reference memory. Mice had to find the way from a start position to a fixed goal through a complex elevated maze. Maze arms were $3 \mathrm{~cm}$ wide and $55 \mathrm{~cm}$ above the floor. The maze had 12 choice points and the distance from the start to the goal was $400 \mathrm{~cm}$. At the goal, mice were food-rewarded. A trial was complete after mice had reached the goal or after $10 \mathrm{~min}$. An error was every complete (whole body) entry into a cul-de-sac. The room was brightly lit and landmarks on the walls of the experimental room served as distal cues. Other procedural details were the same as during radial-maze learning. Animals were given 10 trials, one trial daily.

\subsubsection{Complex alley maze (LAB2)}

Mice had to learn a route through a complex alley maze to their home-cage, placed at the end of the maze. The route was stable from trial to trial and thus required spatial reference memory. The maze comprised a standard cage $(37 \mathrm{~cm} \times 21 \mathrm{~cm} \times 15 \mathrm{~cm})$, two tunnels and a larger central cage $(56 \mathrm{~cm} \times 32 \mathrm{~cm} \times 18 \mathrm{~cm})$. The cages were divided into several fields by Plexiglas walls with holes leading to adjacent fields. Both cages were connected with a tunnel. Another tunnel led out of the maze back to the home-cage. There was one correct way through the maze and there were several dead ends. At the goal the observer opened a door 
and the mice were allowed to re-enter their home-cage as reward. A trial was completed after mice had reached the goal or after $20 \mathrm{~min}$. Observations were conducted using digital imaging techniques with automated animal tracking software (see above). Animals were given three trials, one acquisition trial followed $2 \mathrm{~h}$ later by a second trial reflecting an early state of long-term memory. The third trial was conducted $24 \mathrm{~h}$ after the first trial. Number of errors (an error was counted for each time the mouse entered the first field of a path leading to the wrong direction), number of total field entries and time used for each trial were calculated by means of a macro written in VBA (Visual Basic for Applications) in a MS-Excel spreadsheet holding the $x$ - and $y$-coordinates of the tracked animal.

\subsubsection{Radial maze (LAB1)}

Mice were tested for spatial working memory on an 8arm radial-maze [33], in a 'sampling without replacement' procedure. The radial maze was an elevated maze as previously described [38], but adjusted in size (arms: $10 \mathrm{~cm}$ wide and $50 \mathrm{~cm}$ long; central platform: $30 \mathrm{~cm}$ in diameter) for mice. For each mouse, the same five arms were baited on each trial, and the other three arms were never baited. Re-entry into a previously baited (now empty) arm was defined as 'working memory' error. Entries into never-baited arms were counted as 'spatial reference memory' errors. A trial was completed when all baits had been found or after $10 \mathrm{~min}$, whichever came sooner. Procedural details were the same as during Barnes maze learning except that mice had been food-deprived overnight. Animals were given 10 trials, one trial per day.

\subsection{Spatial memory and exploration of feeding sites under semi-naturalistic conditions}

The spatial behaviour of mice under semi-naturalistic conditions was measured in a large outdoor pen at the "Chisti Les" field station in Bubonizi, Western Russia [16]. Subjects were lightly anaesthetised with methoxiflurane and subcutaneously injected with glass-covered microtransponders (9 $\mathrm{mm}$ long and $1 \mathrm{~mm}$ diameter; UKID System Collinson \& Co., Riverside Industrial Park, Catterall, Preston, UK). Such passive-integrated transponders are routinely used for identification of individual rodents in laboratory and field studies. The mice were then released during July and August into a large outdoor pen equipped with feeding sites containing antennas that detected the visits of individual mice. The pen measured $20 \mathrm{~m} \times 20 \mathrm{~m}$ and had escape-proof walls of $100 \mathrm{~cm}$ above ground, and $50 \mathrm{~cm}$ below the surface. The surface was covered by grass and contained a number of wooden blocks and planks offering protected pathways. Access to the pens was barred to terrestrial predators by means of an electrical fence but avian predators had free access. The pen contained one shelter $(3 \mathrm{~m} \times 3 \mathrm{~m}, 50-70 \mathrm{~cm}$ deep $)$ with a roof. The shelter was filled with hay, branches and wooden boxes.
The distribution of antenna sites (see Section 3; Fig. 7A) included two locations (Nos. 3 and 7) within the shelter, two locations in the most distant corners of the pen (Nos. 1 and 5), and four locations closer to the shelter (Nos. 2, 4, 6, and 8). Each detector antenna was integrated into a PVC tube framing a square of $30 \mathrm{~cm} \times 30 \mathrm{~cm}$. The transponder antennas were scanned continuously for detection of signals by a mechanical multiplexer (UKID System Collinson \& Co.) placed beneath a central interface connected to a batteryoperated, portable computer located in a tent outside the pen. Upon detection of a transponder signal, the computer recorded the individual mouse code and the time of the visit, during an experimental period of 24 days.

Antenna sites were baited with approximately $100 \mathrm{~g}$ of wheat grain according to the following schedule: from days 1 to 11 , food was delivered within the shelters at antennas 3 and 7. From days 12 to 18 , food was only given in the two most remote sites (Nos. 1 and 5). From days 19 to 23, feeding sites were located at antennas 6 and 8, situated closer to the shelter, and on day 24 , the food was delivered again inside the shelters. Variables presented here are the mean latency for first time visits to selected locations (see Section 3 for sequence) and the number of mice recorded, at least once per day, at any of the antennas (providing a control of the population size). Food was always delivered at two symmetrical locations since mice prefer to share resources according to peer groups [16].

\subsection{Statistics}

In order to control for possible differences in the BC1deficient lines due to genetic drift, data analysis focused on pooled samples, but the results were also always checked for line-dependent differences. Depending on the data, appropriate non-parametric or parametric statistics were used. A significance-level $(P)$ of 0.05 was selected. Post-hoc comparisons of multifactorial, non-parametric data sets were done using multiple Mann-Whitney $U$-tests, significance levels being corrected by means of a sequential Bonferroni method [39]. Data from spatial learning experiments were analysed with ANOVAs with between lines differences as the independent factor and blocks of trials at different stages of learning as a repeated measure. Survival analysis in the outdoor enclosure was conducted by means of a Kaplan-Meier survival analysis with a log-rank test for group differences.

\section{Results}

\subsection{General health}

General health of BC1-deficient animals was monitored to assure that behavioural phenotyping was not compromised by non-behavioural parameters. The assessment of the general health state, gross sensory functions, reflexes and motor abilities did not reveal any significant differences between 
BC1-deficient and wild-type mice. In addition, we did not detect any general dysfunctions that could be ascribed to the genetic background of the animals (data not shown). In one of the three BC1-deficient lines (line 13) we observed cataracts in about $5 \%$ of the animals [41]. These mice were excluded from behavioural experimentation.

\subsubsection{Flash visual evoked potentials (FVEP)}

In order to further assess non-apparent visual deficits we examined mice by FVEP. Visual evoked potentials are frequently used to characterise the whole visual pathway function, in particular the ability of the optic nerve to conduct the nerve signals [2]. The amplitude of flash visual evoked potentials (FVEP) depends mainly on the quality of light perception by the eye and cortical processing, whereas the speed of both conduction via the optic nerve and cortical processing determines latency. Three groups of mice were used for the measurement of FVEP: wild-type $(n=11)$, BC1deficient animals from line 13 without cataracts $(n=11)$, and BC1-deficient mice (line 13) with cataracts $(n=11)$. Analyses did not reveal differences in amplitude between wild-type animals $(128 \pm 33 \mu \mathrm{V})$ and BC1-deficient animals without $(120 \pm 47 \mu \mathrm{V})$ and with cataracts $(121 \pm 33 \mu \mathrm{V})$. BC1-deficient animals without cataracts exhibited slightly prolonged latencies ( $33 \pm 14 \mathrm{~ms})$ as compared to wild-type animals $(27 \pm 9 \mathrm{~ms})$. However, these differences were not statistically significant $(P>0.4)$. As expected, mice with cataracts $(46 \pm 15 \mathrm{~ms})$ showed significantly prolonged latencies $(P<0.001$ compared to wild-type, $P<0.02$ compared to $\mathrm{BC} 1$-deficient mice without cataracts). Only mice devoid of cataracts were used for any other tests.

\subsubsection{Daily activity in the laboratory}

BC1-deficient and wild-type mice did not differ in daily activity rhythm. Both BC1-deficient $(n=28)$ and wild-type animals $(n=12)$ displayed a similar pattern of spontaneous locomotor activity (case study shown in Fig. 9A). Compared to other strains of laboratory mice (including strain C57BL/6J) that were analysed using the same method (L. Lewejohann, unpublished data) a pronounced nocturnal activity pattern did neither occur in wild-types nor in knockout mice.

\subsection{Locomotion, exploration and anxiety}

\subsubsection{Barrier test}

In the barrier test BC1-deficient mice were less prone to spontaneous exploration than controls. Ninety-one male mice (controls: $n=24$; line 6: $n=20$; line 13: $n=23$; line 15: $n=24$ ) and 104 female mice (controls: $n=28$; line 6: $n=24$; line 13: $n=28$; line 15: $n=24$ ) were tested. These animals had been housed under enriched conditions (see Section 2) in the breeding colony of LAB2. On average, $\mathrm{BC} 1$-deficient mice took longer to cross the barrier than controls $(U=2758.5, P<0.01$; Fig. 1A). These results indicate a lower spontaneous exploratory activity in mutant mice. However, with lines entered singly $(H=14.37$, d.f. $=$
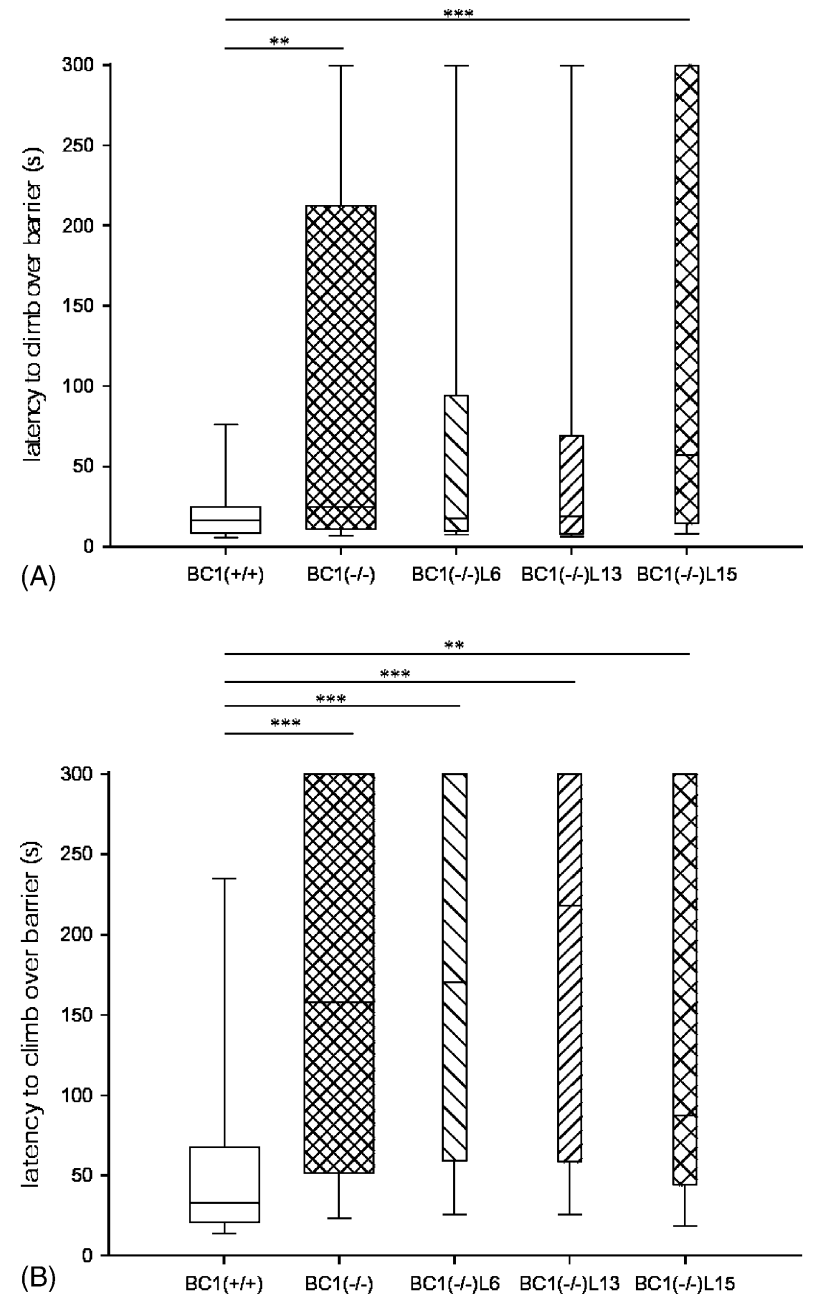

Fig. 1. Barrier test. BC1-deficient mice reared in non-enriched conditions show significantly longer latencies to climb over a barrier than control mice. Latencies to climb over a barrier are given as box plots. Each box represents the 25 th -75 th percentile, and the horizontal line across the box is the median (50th percentile). Whisker lines extending below and above each box represent the 10th and 90th percentile indicating the data-range. (A) In mice kept under enriched conditions, latencies are longer in $\mathrm{BC} 1$-deficient mice $(\mathrm{BC} 1(-/-))$ (pooled data) in comparison to control $(\mathrm{BC} 1(+/+))$ animals. However, separation for all three lines reveals a significantly longer latency in BC1-deficient mice of line 15 (BC1(-/-)L15) as compared to controls but not in line $13(\mathrm{BC} 1(-/-) \mathrm{L} 13)$ and line 6 (BC1(-/-)L6); ${ }^{* *} P<0.01,{ }^{* * *} P<0.001$; Mann-Whitney $U$-test, two-tailed; $\mathrm{BC} 1(+/+): n=24 ; \mathrm{BC} 1(-/-): n=67 ; \mathrm{BC} 1(-/-) \mathrm{L} 6$ : $n=20$; BC1(-/-)L13: $n=23$; BC1(-/-)L15: $n=24$. (B) A repeat of the barrier test with mice reared in standard laboratory cages without additional enrichment revealed a significantly longer latency to climb over the barrier in pooled data from $\mathrm{BC} 1$-deficient mice $(\mathrm{BC} 1(-/-))$ as opposed to control $(\mathrm{BC} 1(+/+))$ animals. This was the case for all three lines. ${ }^{* *} P<0.01,{ }^{* * *} P<0.001$; Mann-Whitney $U$-test, two-tailed; $\mathrm{BC} 1(+/+)$ : $n=40 ; \mathrm{BC} 1(-/-): n=120 ; \mathrm{BC} 1(-/-) \mathrm{L} 6: n=40 ; \mathrm{BC} 1(-/-) \mathrm{L} 13$ : $n=40 ; \mathrm{BC} 1(-/-) \mathrm{L} 15: n=40$.

$3, P<0.005)$, this average lower activity was mainly due to a highly significant difference between line 15 and controls ( $U=701, P<0.0001$ ), whereas line 6 and line $13 \mathrm{did}$ not differ significantly from controls (line 6: $U=946, P>0.1$; line 13: $U=1111.5, P>0.15$; Fig. 1 A). 
In a second experiment 20 male and 20 female mice from each line were housed in LAB2 in standard laboratory cages without additional enrichment in order to control for effects of different environmental experiences. BC1-deficient mice took significantly longer to climb over the barrier than the wild-type mice $(U=1159, P<0.001)$. This effect was true for all three lines $(H=26.272$, d.f. $=3, P<0.001$; line 6: $U=360.5, P<0.001$; line 13: $U=333.5, P<0.001$; line 15: $U=465, P<0.002$ ) (Fig. 1B). In summary, these results suggest that $\mathrm{BC} 1$-deficient animals exhibit reduced exploratory activity.

\subsubsection{Open-field}

In general, BCl-deficient mice did not differ in the total amount of ambulation in open-field tests. To examine spatial exploration of a new environment we used the openfield test. The total amount of ambulation was taken as a measure of locomotor activity. The tendency to avoid the centre of the open-field was considered an index of anxiety. In LAB 1, 45 male mice were examined (controls: $n=11$; line 6: $n=10$; line 13: $n=12$; line 15: $n=12$ ). There was no difference in overall activity, neither with pooled data from BC1-deficient mice ( $U=140.5, P>0.2$; Fig. $2 \mathrm{~A})$, nor with lines entered singly $(H=2.53$, d.f. $=3, P>0.4$; Fig. 2A). However, the proneness to explore the centre of the open-field was significantly reduced in BC1-deficient mice compared to wild-types. With pooled data, there was a significant difference between controls and BC1-deficient mice $(U=97.5, P<0.02$; Fig. 2A). With lines entered singly, this effect was marginally significant $(H=7.26$, d.f. $=3, P=0.06$;) and further pairwise comparisons showed that line $13(U=30.0, P<0.05)$ and line $15(U=$ $26.5, P<0.02)$, but not line $6(U=41.0, P>0.3)$ differed from controls. With sequential Bonferroni correction, only the difference between controls and line 15 was significant (Fig. 2A).

In LAB2, 76 male mice (controls: $n=16$; line 6: $n=$ 20; line 13: $n=16$; line 15: $n=24$ ) and 92 female mice (controls: $n=20$; line 6: $n=24$; line 13: $n=24$; line 15: $n=24)$ were tested. There was no significant difference between wild-type and pooled BC1-deficient mice in overall activity measured by path-length (Fig. $2 \mathrm{~B} ; U=2018, P>$ $0.15)$ and mean-velocity $(U=2018, P>0.15)$.

The time spent in the centre did not vary significantly with pooled data from all lines compared to controls $(U=$ $2217.5, P>0.5)$. With lines entered singly there were significant differences $(H=27.29, U<0.0001)$. Further pairwise comparison of $\mathrm{BC} 1$-deficient lines with wild-type controls revealed that line 6 differed significantly in spending more time in the centre $(U=469.5, P<0.002)$ than controls. Line 13 spent less time in the centre than wild-types $(U=497, P<0.05)$. Line 15 did not differ from wild-types $(U=805, P>0.5)$ (Fig. 2B).

Overall, BC1-deficient mice did not differ in the total amount of ambulation, while data from LAB1 revealed a trend of BC1-deficient mice to avoid open spaces.
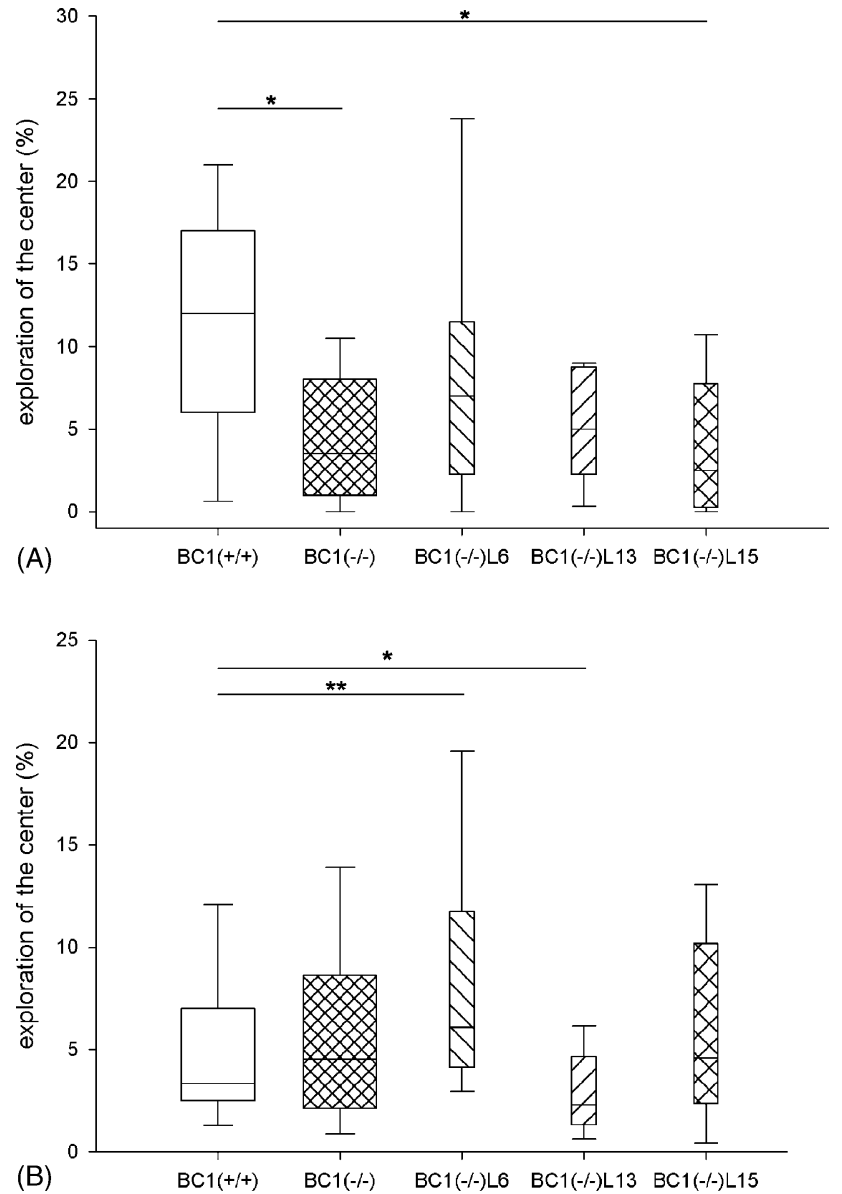

Fig. 2. Open-field: exploration of the centre. BC1-deficient mice do not differ from controls in centre exploration of the open-field test. Box plots showing the proportion of exploration time in the centre of the open-field. (A) In LAB 1 exploration of the centre was measured as proportion of time spent in the centre fields during a period of $5 \mathrm{~min}$. BC1-deficient mice $(\mathrm{BC} 1(-/-))$ mice spent less time in the centre than controls $(\mathrm{BC} 1(+/+))$. With lines entered singly the difference was statistically significant only between controls and line 15 (BC1(-/-)L15); ${ }^{*} P<0.05$; Mann-Whitney $U$-test, two-tailed; BC1(+/+): $n=11$; BC1(-/-): $n=34$; BC1(-/-)L6: $n=10$; BC1(-/-)L13: $n=12 ; \mathrm{BC} 1(-/-)$ L15: $n=12$. (B) In LAB2 exploration of the centre was measured as proportion of time spent in a region more than $10 \mathrm{~cm}$ from the walls during a period of $10 \mathrm{~min}$. Pooled data from BC1-deficient mice $(\mathrm{BC} 1(-/-))$ mice did not differ from controls $(\mathrm{BC} 1(+/+))$. With lines entered singly line $6(\mathrm{BC} 1(-/-) \mathrm{L} 6)$ differed significantly from controls in spending more time in the centre while line $13(\mathrm{BC} 1(-/-) \mathrm{L} 13)$ spent less time in the centre than controls. ${ }^{*} P<0.05,{ }^{* *} P<0.01$; Mann-Whitney $U$-test, two-tailed; $\mathrm{BC} 1(+/+)$ : $n=36$; BC1(-/-): $n=132$; BC1(-/-)L6: $n=44$; BC1(-/-)L13: $n=40 ; \mathrm{BC} 1(-/-) \mathrm{L} 15: n=48$.

\subsubsection{Elevated plus-maze}

The elevated plus-maze revealed higher levels of anxiety in BCl-deficient mice. The proportion of open arm versus total arm entries serves as a measure of anxiety. Forty-five male mice were tested in LAB1 (controls: $n=11$; line 6: $n=10$; line 13: $n=12$; line 15: $n=12$ ). There was no difference in overall activity as measured by total number of arm entries, neither with pooled data $(U=169, P>0.6)$ nor with lines entered singly $(H=4.15$, d.f. $=3, P>$ 

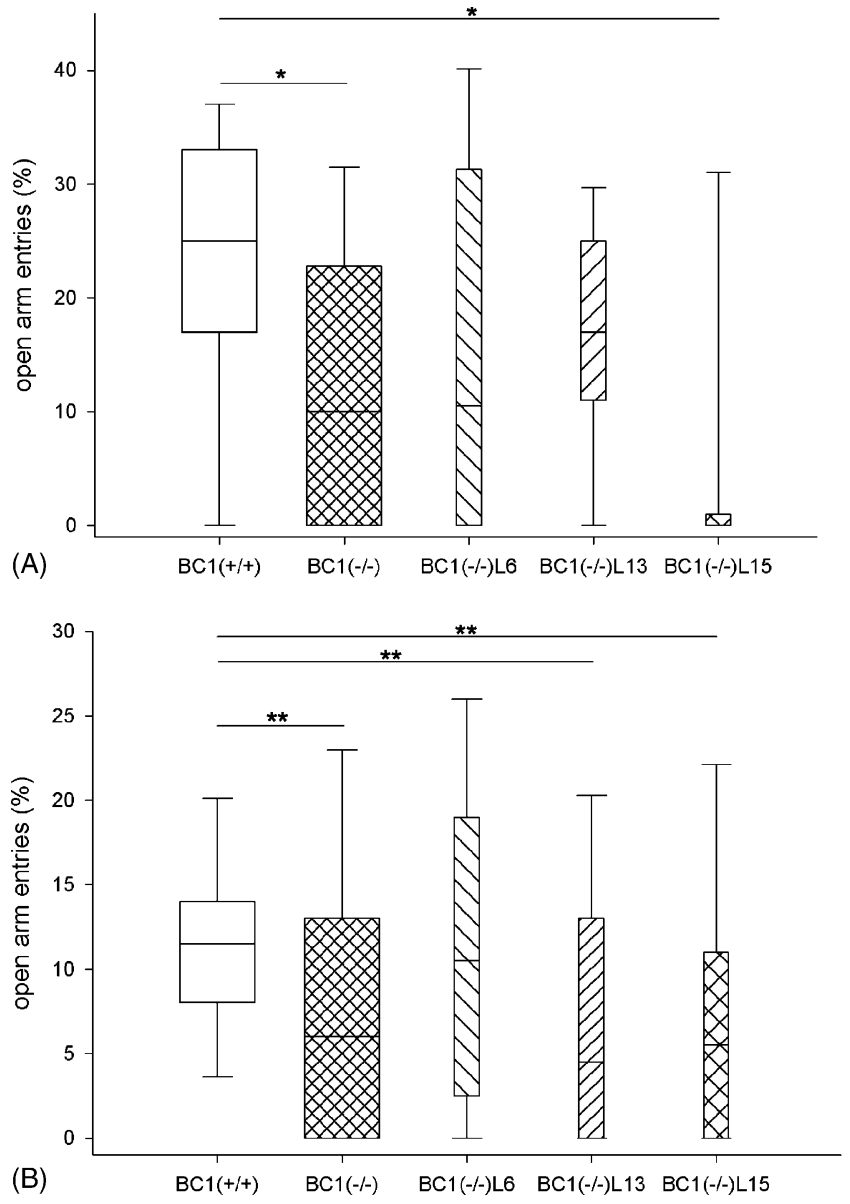

Fig. 3. Elevated plus-maze. Box plots showing the percentage of entries into the open arms of an elevated plus-maze. (A) In LAB1 controls $(\mathrm{BC} 1(+/+))$ were more likely to choose the open arms than $\mathrm{BC} 1$-deficient mice $(\mathrm{BC} 1(-/-))$. With lines entered singly the difference was statistically significant only between controls and line 15 (BC1(-/-)L15); ${ }^{*} P<0.05$; Mann-Whitney $U$-test, two-tailed; $\mathrm{BC} 1(+/+): n=11$; BC1 $(-/-): n=34 ; \mathrm{BC} 1(-/-) \mathrm{L} 6: n=10 ; \mathrm{BC} 1(-/-) \mathrm{L} 13: n=12$; $\mathrm{BC} 1(-/-) \mathrm{L} 15: n=12$. (B) In LAB2 controls $(\mathrm{BC} 1(+/+))$ were more likely to choose the open arms than BC1-deficient mice (BC1(-/-)). With lines entered singly the difference was statistically significant between controls and line $13(\mathrm{BC} 1(-/-) \mathrm{L} 15)$ and between controls and line $15(\mathrm{BC} 1(-/-) \mathrm{L} 15) ;{ }^{* *} P<0.01$; Mann-Whitney $U$-test, two-tailed; $\mathrm{BC} 1(+/+): n=48 ; \mathrm{BC} 1(-/-): n=132 ; \mathrm{BC} 1(-/-) \mathrm{L} 6: n=44$; BC1(-/-)L13: $n=49$; BC1(-/-)L15: $n=39$.

0.2). BC1-deficient mice entered open arms less frequently than wild-type mice (pooled data: $U=109, P<0.05$; Fig. 3A). With lines entered singly, the proportion of open arm entries versus total arm entries (as a measurement for anxiety) also varied among lines $(H=9.55$, d.f. $=3, P<$ 0.025). Further pair wise comparison of BC1-deficient lines with controls showed that this difference was mainly due to a very low open arm exploration in line $15(U=25.5$, $P<0.01)$, while line $6(U=39, P>0.2)$ and line 13 $(U=44.5, P>0.1)$ did not differ from controls (Fig. 3A).

In LAB2, 80 male mice (controls: $n=24$; line 6: $n=20$; line 13: $n=21$; line 15: $n=15$ ) and 100 female mice (controls: $n=24$; line 6: $n=24$; line 13: $n=28$; line
15: $n=24)$ were also tested in the elevated plus-maze. BC1-deficient mice (pooled data) showed fewer arm entries (open and closed) compared to wild-types ( $U=2404.5$, $P<0.02)$. With lines entered singly $(H=8.48$, d.f. $=3$, $P<0.05)$ a pairwise comparison showed that this difference was mainly due to line 15 ( $U=613, P<0.005)$. Neither line $6(U=860.5, P>0.1)$ nor line $13(U=931, P>0.1)$ differed significantly from controls (data not shown).

With pooled data, BC1-deficient mice showed more anxiety-related behaviour expressed as the proportion of open arms versus total arms explored (Fig. 3B; $U=2322$, $P<0.01)$. With lines entered singly, the proportion of open arm entries versus total arm entries differed significantly $(H=13.13$, d.f. $=3, P<0.005)$. Further pair wise comparison of BC1-deficient lines with controls showed that this difference was mainly due to a very low exploration of open arms in line $13(U=754.5, P<0.005)$ and line 15 $(U=587.5, P<0.002)$, while line $6(U=980, P>0.5)$ did not differ from controls (Fig. 3B). In general, we observed a higher level of anxiety in BC1-deficient mice.

\subsection{Spatial memory in mazes}

Five tests using different mazes assessed several aspects of spatial memory. In the Barnes maze and the Morris water maze, reference memory for a single spatial location was examined. During the multiple T-maze and the complex alley maze, reference memory for a complex route was relevant. The radial-maze test evaluated spatial working memory for multiple feeding sites. In all tests we found no impairment of spatial memory in BC1-deficient mice. When differences in behavioural scores occurred, they could be traced back to reduced exploratory behaviour.

\subsubsection{Barnes maze}

In the Barnes maze, BCl-deficient mice made fewer errors than controls. In the Barnes maze, 9 controls (4 male, 5 female) and $14 \mathrm{BC} 1$-deficient mice (line 6: 3 males, 5 females; line 13: 3 males, 3 females) were tested in LAB1. Fig. 4 presents the error scores in the Barnes maze. When control mice were compared with the combined $\mathrm{BC} 1$-deficient mice, ANOVA revealed an effect of BC1 genotype $(F(1,21)=$ $8.29, P<0.01)$. With lines entered singly, there also was an effect of genotype $(F(2,20)=5.01, P<0.02)$. Further exploration of this effect showed a significant difference between controls (wild-type) and BC1-deficient L13 mice $(P<0.01)$ but not between controls and L6 mice. An analysis of errors over consecutive days showed that BC1deficient mice started with an error level close to 6.5 , which is the expectation for random choices (the maze comprises 12 holes). Wild-type mice committed considerably more errors than expected by random. Consequently results are biased by differences in exploratory behaviour, too. This indicates that behavioural strategies like exploring many holes before choosing the goal led to errors, and cannot be explained by differences in memory. 


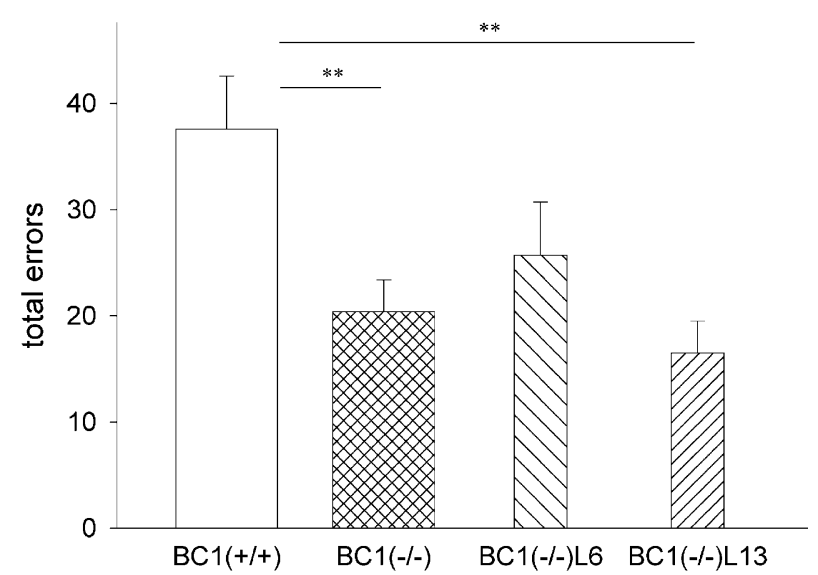

Fig. 4. Barnes maze. Number of errors during learning of the Barnes maze (means \pm S.E.M.). BC1(-I-) mice differed from controls. ${ }^{* *} P<0.01$; ANOVA. $\mathrm{BC} 1(+/+): n=9 ; \mathrm{BC} 1(-/-): n=14$; with lines entered singly, $\mathrm{BC} 1(-/-) \mathrm{L} 13$ but not $\mathrm{BC} 1(-/-) \mathrm{L} 6$ differed from controls. ${ }^{* *} P<0.01$; ANOVA followed by pair wise comparison with the LSD test. $\mathrm{BC} 1(+/+)$ : $n=9 ; \mathrm{BC} 1(-/-) \mathrm{L} 6: n=8 ; \mathrm{BC} 1(-/-) \mathrm{L} 13: n=6$. However, further analysis points to different exploratory behaviour rather than differences in learning of the task.

\subsubsection{Morris water maze}

Morris water maze reveals equal acquisition and probe trial scores for spatial memory in BCl-deficient mice and controls. Expression of BC1 RNA in some areas of the hippocampus [45] prompted us to check whether BC1-deficient mice might show impairments in water maze learning where mice must learn to find a submerged platform using distal visual cues. Water maze learning requires complex adaptive responses and involves multiple memory systems. Cerebral malfunctions can impair many of these steps, but it is thought that hippocampal impairment is specifically reflected in poor probe trial scores when the mice are searching over the former position of a removed platform [27].

Forty male mice (20 wild-type, $20 \mathrm{BC} 1$-deficient mice; line 13: 10; line 15: 10) were tested in the water maze. As shown in Fig. 5, BC1-deficient mice showed neither impaired learning (Fig. 5A), nor impaired spatial memory as evidenced by probe trial scores comparable to those of the control mice (Fig. 5B). In addition, thorough analysis of all strategies known to affect water maze learning did not reveal any differences between knock-out and control mice. Likewise, swimming speed and the propensity for motionless floating were the same for both groups.

\subsubsection{Multiple T-maze. BC1-deficient mice did not dif-} fer from controls in reference memory for a complex route in the multiple T-maze. Fig. 6A shows the number of errors during multiple T-maze learning. Nine wild-type control mice and 8, 7, and 6 mice of lines L6, L13, and L15, respectively, were tested. The number of errors decreased over blocks of trials $(F(2,50)=52.23, P<0.0001)$, but there was no differences among the lines $(F(3,25)=2.02, P>0.1)$ and no interactions $(F(6,50)=2.14, P>0.05)$. With pooled data

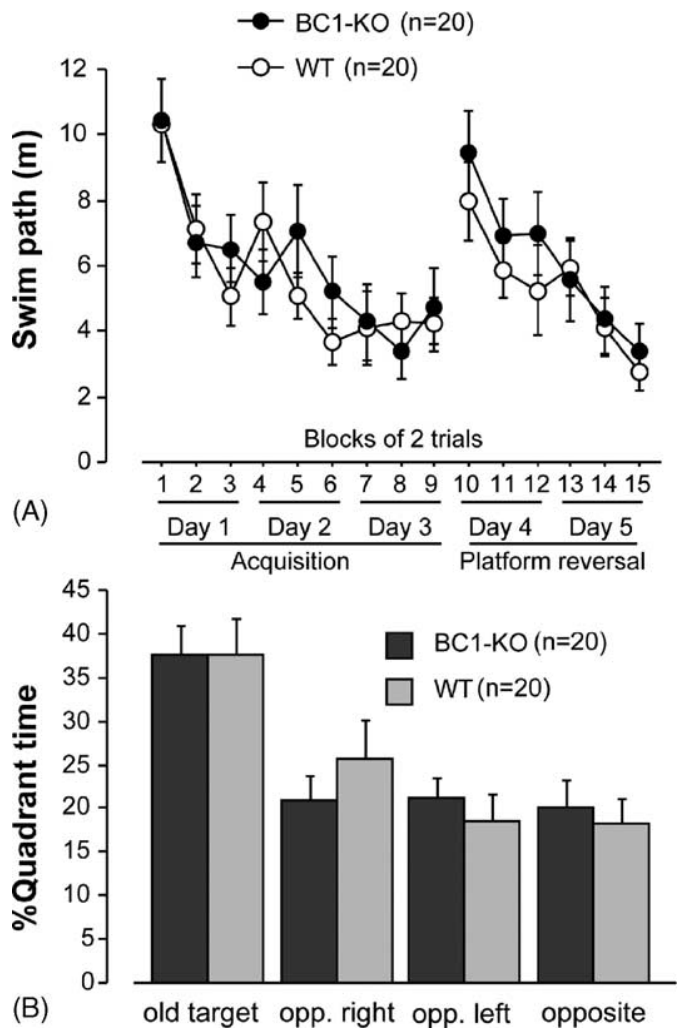

Fig. 5. Morris water maze. (A) Swim path length (mean \pm S.E.M.) during acquisition and after platform reversal learning. Successful learning is indicated by decrease of swim path between trials. (B) Percent time spent in different quadrants during probe trial (first $60 \mathrm{~s}$ of trial 19, the first day of platform reversal). Mean \pm S.E.M.; $\mathrm{BC} 1(+/+): n=20$; $\mathrm{BC} 1(-/-)$ : $n=20$. There was no effect of genotype.

from BC1-deficient animals a similar pattern emerged with a significant effect of trial block $(F(2,54)=43.81, P<$ $0.0001)$, but no BC1 genotype differences $(F(1,27)=0.27$, $P>0.6)$ and no interactions $(F(2,54)=0.14, P>0.8)$.

The latency to trial completion decreased over blocks of trials $(F(2,50)=15.49, P<0.0001)$. There were no overall line differences $(F(3,25)=0.60, P>0.6)$. With pooled $\mathrm{BC} 1$-deficient data there was significant reduction in the latency to trial completion $(F(2,54)=9.44, P<0.0005)$, but there were no BC1 genotype differences $(F(1,27)=0.78$, $P>0.3)$ and no interactions $(F(2,54)=0.11, P>0.8)$. Thus, both, controls and BC1-deficient mice learned the task efficiently.

\subsubsection{Complex-alley maze}

The complex-alley maze revealed differences in exploratory behaviour rather than spatial memory. In the complex-alley maze (Fig. 6B), 28 controls (16 males, 12 females) and 84 BC1-deficient mice (line 13: $n=12$ males, 16 females; line 15: $n=12$ males, 12 females; line 6: $n=13$ males, 19 females) were tested (LAB2). All wild-type mice eventually reached their home-cage, whereas 18 BC1-deficient mice (13 of line 15 and 5 of line 13) did not venture much out of the start box within 

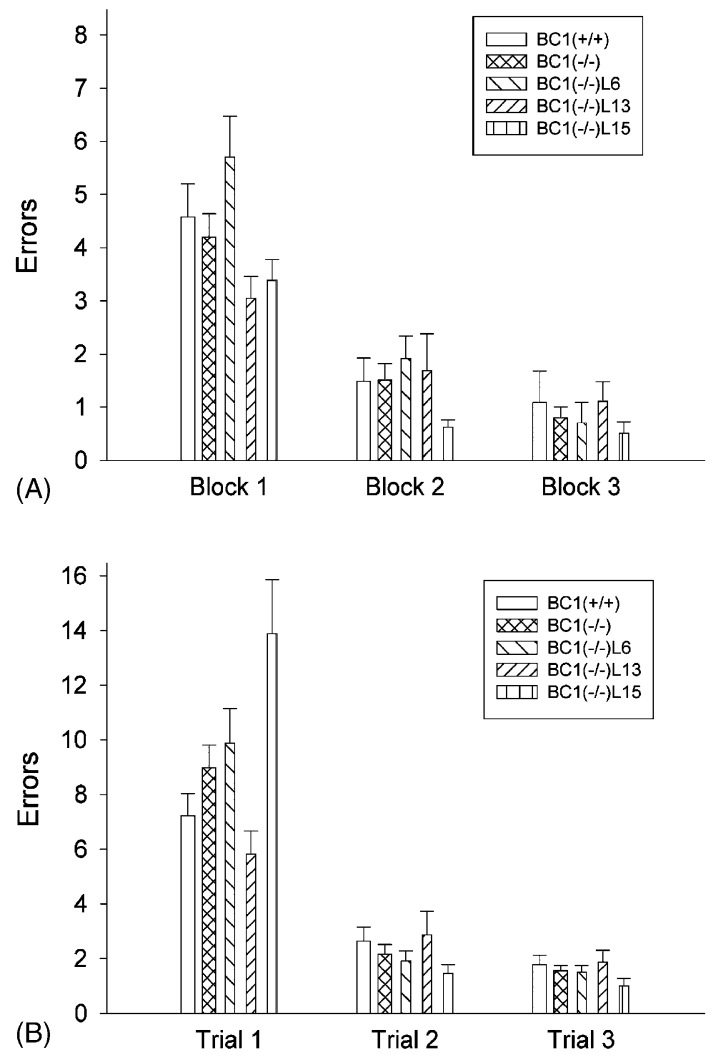

Fig. 6. Route learning. Learning of a complex route in a multiple T-maze (A) and an enclosed alley maze (B). In either task mice learned efficiently as indicated by a decreasing number of errors over consecutive trials or blocks of trials, but there was no effect of genotype. Multiple T-maze: $\mathrm{BC} 1(+/+): n=9 ; \mathrm{BC} 1(-/-): n=21 ; \mathrm{BC} 1(-/-)$ L6: $n=8$; $\mathrm{BC} 1(-/-) \mathrm{L} 13: n=7$; $\mathrm{BC} 1(-/-) \mathrm{L} 15: n=6$. Alley-maze: $\mathrm{BC} 1(+/+)$ : $n=28 ; \mathrm{BC} 1(-/-): n=84 ; \mathrm{BC} 1(-/-) \mathrm{L} 6: n=32 ; \mathrm{BC} 1(-/-) \mathrm{L} 13$ : $n=28 ; \mathrm{BC} 1(-/-) \mathrm{L} 15: n=24$.

20 min indicating a very low inclination to explore. Only those mice that completed the first trial were included in a second and third trial. An ANOVA with genotype as independent factor and tests as a repeated measure revealed significant learning measured as a decreased latency to reach the home-cage $(F(2,180)=67.59, P<0.0001)$, the number of fields entered $(F(2,178)=56.31, P<0.0001)$, and the number of errors $(F(2,178)=56.85, P<0.0001)$. However, there was no main effect of genotype (time: $F(1,90)=1.73, P>0.1$; fields: $F(1,89)=0.02, P>0.8$; errors: $F(1,89)=0.54, P>0.4)$ and no interaction. Thus, the complex-alley maze did not reveal differences in spatial memory; instead reduced exploratory behaviour, compared to controls, was observed in the $\mathrm{BC} 1$-deficient mice.

\subsubsection{Radial maze}

The working memory performance of BCl-deficient mice was comparable to that of controls. Thirty-nine males were tested in LAB1 for radial maze learning (controls: $n=10$; line 6: $n=10$; line 13: $n=9$; line 15: $n=10$ ). Errors decreased over blocks of trials and the number was well below random performance in the last block of three trials. With pooled data, ANOVA revealed a significant effect of trial block $(F(2,74)=5.88, P<0.005)$, but no effect of $\mathrm{BC} 1$ genotype $(F(1,37)=0.03, P>0.8)$ and no interaction $(F(2,74)=0.22, P>0.8)$. Similarly, with lines entered singly there was a significant effect of trial block $(F(2,70)=$ $8.94, P<0.0005)$, but no effect of line $(F(3,35)=2.60$, $P>0.05)$, and no interaction $(F(6,70)=0.19, P>0.9)$. The number of reference memory errors remained fairly high (all lines $\sim 2.1$ in the third trial block), but nevertheless decreased significantly $(F(2,70)=2.89, P<0.05)$. We failed to observe any significant differences irrespective of whether the data had been pooled or whether lines were entered separately $(F(3,35)=0.17, P>0.9)$.

\subsection{Spatial memory and exploration of feeding sites under semi-naturalistic conditions}

Control and BC1-deficient mice responded differently to the outdoor environment and to changes in the feeding sites. Forty-eight mice (24 wild-type and 24 BC1-deficient mice from lines 13 and 15 , equal proportions of sexes) were tested. Mice that are released into a large outdoor pen must first learn to find the feeding sites by means of exploration [16]. As mice initially avoid open spaces, food was placed during the first 11 days inside the shelter. Most mice appeared at the feeding sites within a few hours. Yet, in comparison to wild-type mice, BC1-deficient mice showed slightly but significantly shorter latencies to visit these protected food sites (Fig. 7A; $U=158, P<0.001$ ). Exploration of the remaining pen, as assessed by visits to the non-baited antennas outdoors, took longer for all mice. However, under these conditions, $\mathrm{BC} 1$-deficient mice took much longer to visit non-baited distant antenna sites than the wild-types. For example, the median latency to visit any one of the antennas placed outside the shelters (Nos. 1, 2, 5, 6, or 8) was 3.03 days for the wild-type controls, but was twice as long for the BC1-deficient mice (Fig. 7A, 6.05 days; $U=164$, $P<0.02)$.

When mice have learned the location of given feeding sites, reversal of these locations provides a partial measure of flexibility. The first shifting of the food sources to distant sites (Nos. 1 and 5) occurred at day 12. It then took the control mice a median time of 1.26 days to first visit these sites, while the median latency of the BC1-deficient mice was 2.23 days $(U=95, P<0.01$; Fig. 7B). After this, food was moved to antennas 6 and 8 located closer to the shelter but far away from the previous location (Fig. 7C). This transition was easier for all mice to adapt to, as they appeared at this site after about half a day, the wild-type mice appeared earlier yet not significantly so (Fig. 7C). Finally, food was placed again inside the shelters. It took again about half a day for the mice to appear at these locations, but BC1deficient mice were significantly faster $(U=47, P<0.05$; Fig. 7D). This finding shows that reversal learning in the BC1-deficient mice was location-dependent. 

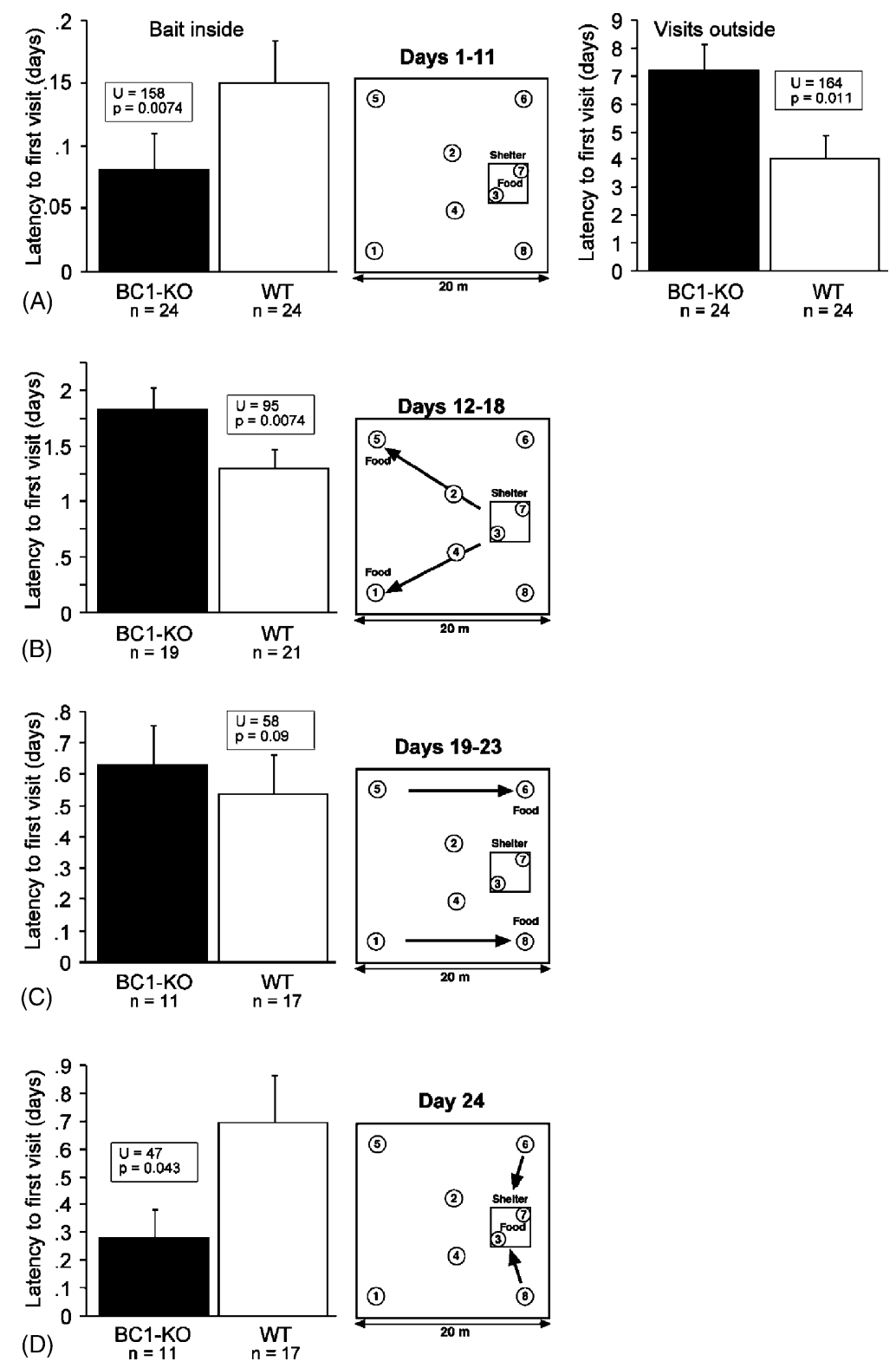

Fig. 7. Exploration and place reversal learning of $\mathrm{BC} 1-\mathrm{KO}$ and wild-type mice in outdoor pens. Means \pm S.E.M. of latencies expressed in days. (A) First 11 days: latency to appear at feeding sites (Nos. 3 and 7) inside the shelter (within hours) and latency to visiting any non-baited site (Nos. 1, 2, 4-6 and 8) outdoors (within several days). (B) First reversal of feeding site to distant locations (Nos. 1 and 5). (C) Second reversal of feeding sites to other distant locations (Nos. 6 and 8). (D) Last food site reversal to shelter (Nos. 3 and 7). Note the earlier appearance of BC1-deficient mice at protected feeding sites and the longer latencies to appear at outdoor sites.

Both groups of mice suffered losses, particularly when they were forced to visit distant feeding sites. The survival was poorer in BC1-deleted mice than it was in controls (Fig. 8). At the end of the experiment, only $46 \%$ of BC1deficient mice remained, while there were $71 \%$ of the control mice. A Kaplan-Meyer survival analysis with a log-rank test for group differences revealed a decreased survival of the mutants $(P<0.05)$. Taken together, the data indicate that BC1-deficient mice are able to quickly locate newly placed food sites and to remember them over many days, being even slightly superior to wild-type mice. However, this occurred only under protected conditions within the shelter. On the other hand, they were very slow to appear at non-baited, distant sites, indicating strongly reduced exploratory behaviour. The decreased exploratory behaviour of BC1-deficient mice and their decreased survival rate in the semi-naturalistic outdoor pen (in year 2000), were subsequently confirmed with all three independent mouse lines in year 2001.

Reduced exploratory activity in BC1-deleted mice is also indicated in the daily activity pattern (Fig. 9). Particularly revealing is the comparison of spontaneous locomotor activity in the laboratory (Fig. 9A) and the exploration of feeding sites (Fig. 9B). There was no difference in the spontaneous locomotor activity in the home-cage, no difference in the 


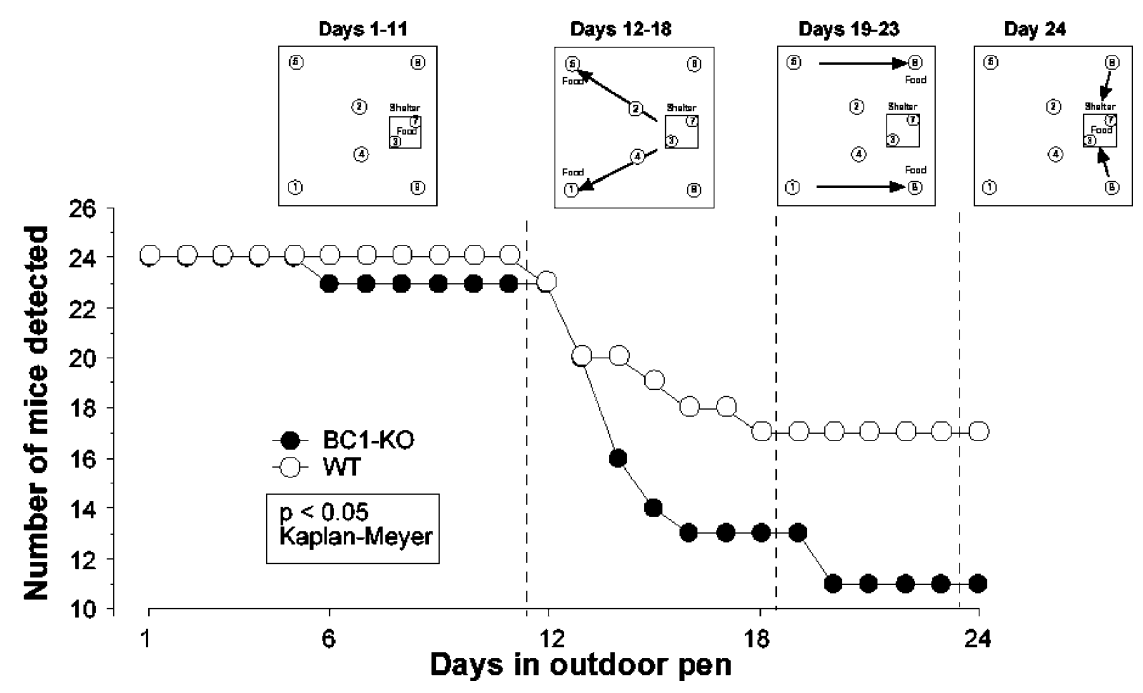

Fig. 8. Survival. Number of BC1-KO and wild-type mice detected at any antenna site during 24 days. Note the decline in numbers after having been forced to feed at distant sites. Overall, BC1-deficient mice experienced higher losses than wild-type mice.

distribution of activity in the outdoor pen over the course of the day, but a marked difference in the amount of feeding site exploration with less exploration in $\mathrm{BC} 1$-deleted mice.

An overview presenting the main findings from all behavioural tests is given in Table 1.

\section{Discussion}

Results from the different laboratory tests reveal an overall consistent picture: BC1-deficient mice showed decreased exploration and higher levels of anxiety, compared to wildtype mice. On the other hand, spatial memory functions were spared. These results were confirmed by the seminaturalistic tests in a large outdoor pen, tests which in addition, demonstrated a reduced survival rate of $\mathrm{BC} 1$-deficient animals.

\subsection{BC1 RNA modulates expression of exploratory behaviour but not spatial learning and memory}

We chose an integrated approach of using complementary tests and concurrent testing in different laboratories to ascertain the validity of all behavioural-phenotypic parameters obtained. In addition, we validated the laboratory findings in a semi-naturalistic setting. Based on this comprehensive approach, we conclude that BC1 RNA plays a role in the regulation of exploratory behaviour. We are aware that we cannot fully rule out subtle physiological deficits in mice lacking the BC1 RNA gene. However, findings from in-depth analysis of sensory and motor neurophysiology (see above) argue against any such deficits as a determinant of the observed behavioural differences. Also, there was no difference in spontaneous locomotor activity in the home-cage, but a clear difference in exploration of feeding sites under semi-naturalistic conditions. Finally, findings from labora- tory tests that specifically probed exploration do not indicate different levels of locomotor activity. In the measures of locomotor activity derived from open-field and elevated plus-maze tests, no effects of BC1 RNA deletion were observed. Conversely, tests specifically addressing exploration indicated a reduction in BC1 RNA-deficient mice.

Exploration is a multifactorial behaviour, which is determined by the pleiotropic action of several genes [13]. "Exploration is evoked by novel stimuli and consists of behavioural acts and postures that permit the collection of information about new objects and unfamiliar parts of the environment" [14]. On one hand, enhanced exploratory behaviour represents increased chances for animals to find life support supplies such as shelters, food, water, escape routes, etc. On the other hand, increased exploratory behaviour may render animals more vulnerable to predators [13].

Elimination of the BC1 RNA gene apparently causes a shift in the balance between the proneness to explore new places and the tendency to avoid the exploration of open spaces. This conclusion is supported by data from several independent tests. Thus, BC1-deficient mice showed reduced exploratory behaviour in the barrier test, the open-field test and the complex-alley maze test, and were reluctant to enter open arms in the elevated plus-maze. Reduced exploratory behaviour may also be mediated by mechanisms regulating anxiety $[6,23]$. Importantly, observations in the laboratory on exploration and anxiety-related behaviour were confirmed by results from the semi-naturalistic outdoor studies. Under stable and protected conditions inside the shelters, the BC1-deficient mice had no difficulties in finding food sites; in fact, they were even faster than wild-type animals (Fig. 7A). While these results do not necessarily indicate superior exploration of BC1-deficient mice under anxiety-free conditions, they certainly show that the mutants do not suffer from some generalised impairment. On the other hand, their delayed appearance at non-rewarded outdoor sites (Fig. 7A) 

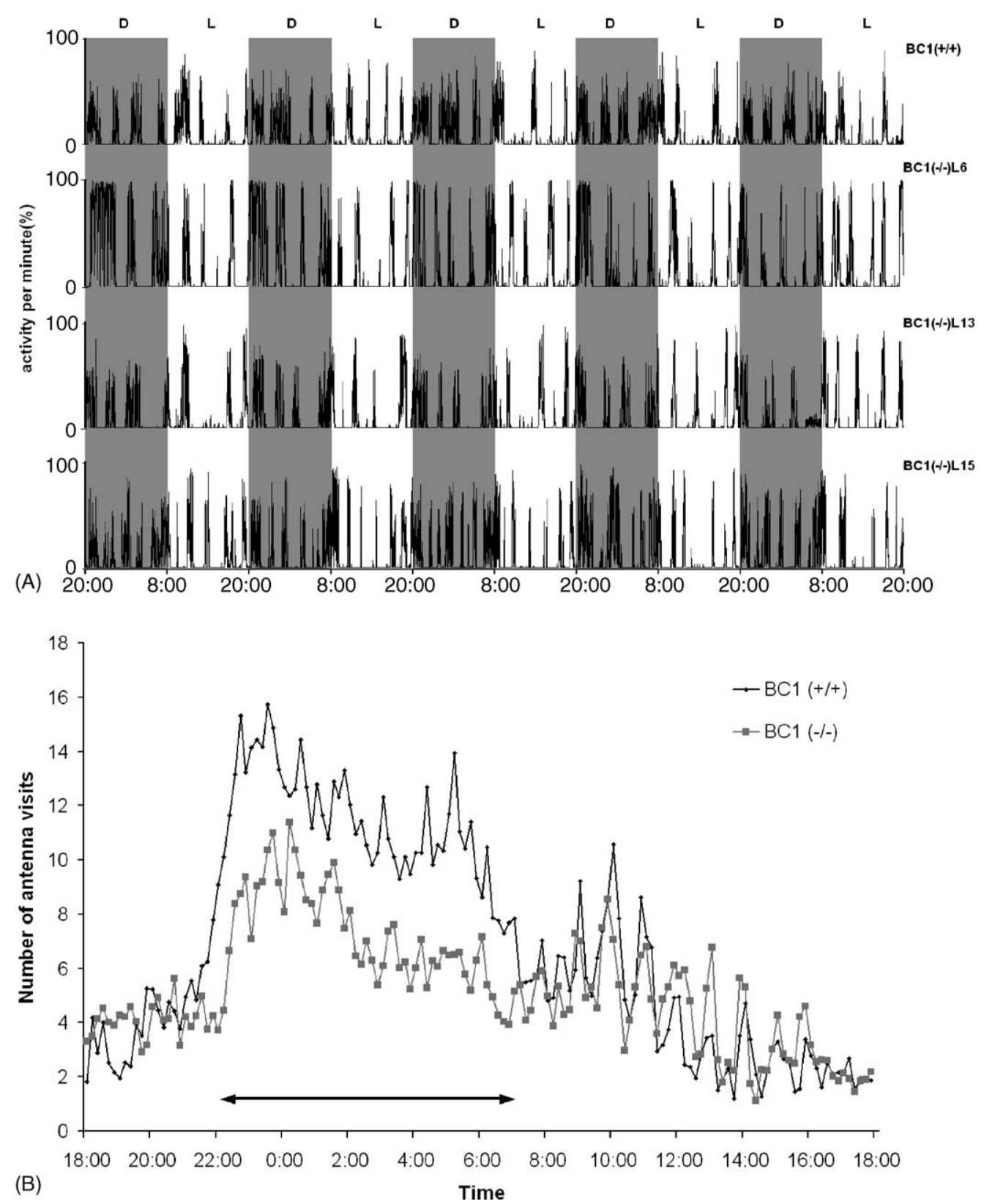

Fig. 9. Daily activity in laboratory cage and semi-naturalistic outdoor pen. (A) In the laboratory, BC1-deficient mice did not differ from controls with respect to daily activity rhythm. Activity was measured for 5 consecutive days during 12:12 h light-dark cycles. The percentage of activity is plotted for each minute. D (gray): dark-phase, L (white): light-phase. Shown here is a representative case study for one wild-type mouse and for one individual of each BC1-deficient line. (B) Under semi-naturalistic conditions wild-type and BC1-deficient exhibited a similar distribution of activity during the day, but, overall, wild-type mice explored considerably more than BC1-deficient mice. $\mathrm{BC} 1(+/+): n=24 ; \mathrm{BC} 1(-/-): n=24$.

is a clear indication of reduced exploration of new distant places. Since spatial learning and memory are apparently intact in these mutants, the impairment must reflect either an inhibition of exploratory tendencies via elevated fear or anxiety, or a genuinely reduced level of exploratory drive.

\subsection{Presumptive links between BCl RNA and the behavioural consequences of its elimination}

Without even considering epistatic consequences [3] of $\mathrm{BC} 1$ RNA deletion, the hypothesised role of $\mathrm{BC} 1 \mathrm{RNA}$ in translation modulation is obviously rather generalised and would apply to all cell types that express the RNA $[21,43-45,48]$. Therefore, effects of the RNA on behavioural phenotype would be determined by the nature of BC1 RNAexpressing cell types, and the nature of the proteins, whose synthesis is subject to BC1 RNA-mediated control in such cells. Thus, the specific impact of BC1 RNA on exploratory behaviour can be expected to reflect expression and function of the RNA in brain areas that subserve such behaviour. Exploratory behaviour strongly depends on septal modulation of the hippocampus [7,42], and because expression of $\mathrm{BC} 1$ 
Table

Summary of behavioural tests

\begin{tabular}{|c|c|c|c|c|c|c|c|c|c|}
\hline \multirow[t]{2}{*}{ Test } & \multirow[t]{2}{*}{ Lab } & \multirow[t]{2}{*}{ Housing conditions } & \multirow[t]{2}{*}{ Pooled data } & \multirow[t]{2}{*}{ Line 6} & \multirow[t]{2}{*}{ Line 13} & \multirow[t]{2}{*}{ Line 15} & \multicolumn{3}{|l|}{ Effect } \\
\hline & & & & & & & Exploration & $\begin{array}{l}\text { Spatial } \\
\text { memory }\end{array}$ & Mortality \\
\hline Barrier & 2 & $\begin{array}{l}\text { Enriched } \\
\text { Standard }\end{array}$ & $\begin{array}{l}+ \\
+\end{array}$ & + & + & $\begin{array}{l}+ \\
+\end{array}$ & KO took longer to climb over barrier & & \\
\hline Open-field (locomotion) & $\begin{array}{l}1 \\
2\end{array}$ & $\begin{array}{l}\text { Standard } \\
\text { Enriched }\end{array}$ & & - & & & Line 6 showed more ambulation & & \\
\hline \multirow[t]{2}{*}{ Open-field (centre) } & 1 & Standard & + & & & + & $\begin{array}{ll}\text { KO were more anxious } & \text { In Lab } 2 \text { line } 6 \text { was } \\
& \text { less anxious }\end{array}$ & & \\
\hline & 2 & Enriched & & - & + & & & & \\
\hline Elevated plus-maze & $\begin{array}{l}1 \\
2\end{array}$ & $\begin{array}{l}\text { Standard } \\
\text { Enriched }\end{array}$ & $\begin{array}{l}+ \\
+\end{array}$ & & + & $\begin{array}{l}+ \\
+\end{array}$ & KO were more anxious & & \\
\hline Barnes maze & 1 & Standard & + & & + & \# & KO made less errors due to low exploration & & \\
\hline Radial maze & 1 & Standard & & & & & & - & \\
\hline Multiple T-maze & 1 & Standard & & & & & & - & \\
\hline Complex alley maze & 2 & Enriched & + & & & + & KO showed low exploration in acquisition trial & - & \\
\hline Water maze & 3 & Standard & & $\#$ & & & & - & \\
\hline \multirow[t]{2}{*}{$\begin{array}{l}\text { Semi-natural outdoor } \\
\text { pen, } 2000\end{array}$} & 3 & $\begin{array}{l}\text { Reared in standard, "max } \\
\text { enriched" outdoor }\end{array}$ & + & $\#$ & & & KO showed reduced exploration & - & \\
\hline & & & + & $\#$ & & & & & Higher mortality \\
\hline \multirow[t]{2}{*}{$\begin{array}{l}\text { Semi-natural outdoor } \\
\text { pen, } 2001\end{array}$} & 3 & $\begin{array}{l}\text { Reared in standard, "max } \\
\text { enriched" outdoor }\end{array}$ & + & & & & KO showed reduced exploration & - & in $\mathrm{KO}$ \\
\hline & & & & & & + & & & $\begin{array}{l}\text { Higher mortality } \\
\text { in } \mathrm{KO}\end{array}$ \\
\hline
\end{tabular}

To analyse behavioural effects of deleting the $\mathrm{BC} 1$ gene in vivo a wide ranging test battery was conducted. With pooled data from all three lines strong effects on exploratory and anxiety related behaviour were found. However, testing lines singly revealed fewer significant results although contradictory findings (indicated by "-") were rare and did not affect pooled data. With regard to learning and memory no effects were found. Mortality was higher in knockout mice as compared to controls in a semi-natural environment tested in the year 2000. A second outdoor test conducted in the year 2001 failed to reproduce this effect for pooled data of all three lines but one line (line 15) showed significantly higher mortality. The symbol "+" indicates significant effects. The symbol "\#" indicates single lines that were not included in the respective test. 
RNA is high in both the septum and specific subfields of the hippocampus, lack of BC1 RNA may produce deficits in this modulation. Furthermore, exploratory drive is attenuated by fear- and aversion-related processes [1], which are governed by local modulation in several subcortically-located brain systems [49]. Amygdaloid nuclei (lateral, basal, accessory basal, and central) that process fear and anxiety responses (for review see [24]) have been shown to express substantial levels of BC1 RNA [26]. It can therefore be surmised that the reduced exploratory behaviour in BC1-negative mice may be, at least in part, a consequence of the absence of the RNA in those nuclei.

\subsection{Variability across different $\mathrm{KO}$-lines}

Three different lines of BC1 RNA-deficient mice were tested. Comparing controls to pooled data from all three lines revealed stronger indications for the conclusions drawn above than a comparison of single lines would have revealed. If we had only compared one line, our conclusions might be quite different depending on whether we would have chosen line 6 or line 15. For example in the elevated plus-maze test higher anxiety was found in line 15 in both laboratories while higher anxiety in line 13 was only found in LAB2. Line 6, however, did not differ significantly from controls with regard to anxiety in neither LAB1 nor LAB2. Therefore, results obtained from only one line have to be treated with caution. Nevertheless, splitting of data results in loss of statistical power. We often observed a trend to the same direction in those lines that did not reveal significant differences. Additionally, contradictory findings were rare (see Table 1). Therefore, our conclusions are cautiously based upon pooled data considering the impact of single lines along with taking advantage of applying several different tests (see below).

\subsection{Variability across similar behavioural tests carried out in different laboratories}

As has been previously shown [12], the same mouse strains under seemingly similar settings may show significantly different behaviour in different laboratories. We performed behavioural testing of the BC1-negative mice in matched and complementary tests in three different laboratories. In general, consistent results were obtained at the different locations. Interestingly, differences between two groups of $\mathrm{BC} 1$-negative mice observed in the barrier test might have been due to differences in their respective rearing conditions. $\mathrm{BC} 1$-deficient mice from all three lines raised in standard cages exhibited significantly longer latencies to climb over the barrier than control mice (Fig. 2B). In contrast, not all BC1-deficient mouse lines raised under enriched conditions differed from control mice (Fig. 2A). Enriched environments stimulate developmental compensatory mechanisms and enhance mice performance on behaviour tasks [37]. However, some of the other tests assessing exploratory behaviour did not reveal statistically significant differences due to rearing conditions. Thus, an overwhelming majority of the data point to decreased exploratory behaviour of BC1-deficient mice compared to control animals.

In terms of methodology, our findings clearly show the usefulness of an approach using a set of tests rather than using single 'hallmark' tests for the evaluation of exploration, anxiety, and spatial memory. Although the overall picture is fairly consistent, the differences in some of the tests indicate that findings from only one test for a behavioural domain could have been quite misleading. For example, without a thorough consideration of exploratory behaviour results from the Barnes maze test might have led to the conclusion that $\mathrm{BC} 1 \mathrm{RNA}$ has some impairing effect on spatial memory. Also, results in the Morris water maze may be confounded by behavioural strategies not due to spatial memory. By comparing the results from different tests one can, however, demonstrate quite convincingly that there were no effects of BC1 RNA deletion on spatial memory.

In the same vein, results from the different exploratory tests give a rather consistent picture, while the variability between the tests indicates that using only the one or other single test might have led to over- or underestimation of the effects of BC1 RNA-deletion on exploratory behaviour.

\subsection{Conclusion}

In summary, the combined results suggest that BC1 RNA contributes to neuronal mechanisms that underlie aptive behaviour of rodents. This conclusion is in line with phylogenetic considerations that argue for an indispensable modulatory role of this RNA. The gene for BC1 RNA appeared comparatively late in evolution, probably not more than 110 million years ago [22,30]. It is nonetheless found in all rodents, with highly conserved spatiotemporal neuronal expression patterns and somatodendritic subcellular localisation $[10,11,45]$. Within the BC1 RNA gene, moreover, the RNA coding region - but not the flanking regions-exhibits a high degree of sequence similarity among rodent species ([30], C. Raabe, B.V. Skryabin and J. Brosius, unpublished observations). Such sequence conservation implies that the BC1 RNA gene conveys a selective advantage. Our results point to the possibility that expression of $\mathrm{BC} 1 \mathrm{RNA}$ in the CNS fulfils a requisite role in the brain by modulating expression of behavioural phenotypes.

\section{Acknowledgements}

We would like to thank Inga Poletaeva for help with the outdoor open pen system, Svetlana Pazhetnova for taking care of mice at the field station; Nadejda Markina and Olga Perepelkina for help with mouse training in the water maze, Peter Bergold for suggesting as early as 1986 that BC1 RNA may modulate animal behaviour, and Marsha Bundman for critical reading and discussion of the manuscript. This work was supported by grants from the Deutsche Forschungsge- 
meinschaft to H.P. (Pr 489/3), the Deutsche Forschungsgemeinschaft (Br 754/2, Kr1624/3-1) and the Volkswagen Stiftung (I/74 040) to J.B., the Deutsche Forschungsgemeinschaft (Sa 389/5) to N.S., the NIH (NS13458) to H.T., the Swiss National Science Foundation, SCOPES and the NCCR "Neural plasticity and repair" to H.-P.L. P.H. was supported by a grant from the Federal Ministry of Education and Research (Fö. 01KS9604/0) and the Interdisciplinary Center of Clinical Research Münster (IZKF Project No. F 7).

\section{References}

[1] Aitken PP. Aversive stimulation and rats' preference for areas differing in novelty-value and brightness. Anim Behav 1974;22:731-4.

[2] Aminoff MJ, Goodin DS. Visual evoked potentials. J Clin Neurophysiol 1994;11:493-9.

[3] Anholt RR, Dilda CL, Chang S, Fanara JJ, Kulkarni NH, Ganguly I, et al. The genetic architecture of odor-guided behavior in Drosophila: epistasis and the transcriptome. Nat Genet 2003;35:180-4.

[4] Barnes CA. Memory deficits associated with senescence: a neurophysiological and behavioral study in the rat. J Comp Physiol Psychol 1979;93:74-104.

[5] Benus RF, Bohus B, Koolhaas JM, van Oortmerssen GA. Heritable variation for aggression as a reflection of individual coping strategies. Experientia 1991;47:1008-19.

[6] Blanchard RJ, Kelley MJ, Blanchard DC. Defensive reactions and exploratory behavior in rats. J Comp Physiol Psychol 1974;87:112933.

[7] Bland BH, Oddie SD. Theta band oscillation and synchrony in the hippocampal formation and associated structures: the case for its role in sensorimotor integration. Behav Brain Res 2001;127: 119-36.

[8] Brosius J. Transmutation of tRNA over time. Nat Genet 1999;22:8-9.

[9] Brosius J. The contribution of RNAs and retroposition to evolutionary novelties. Genetica 2003;118:99-116.

[10] Brosius J, Tiedge H. Neural BC1 RNA: dendritic localization and transport. In: Lipshitz HD, editor. Localized RNAs. Austin, TX: R.G. Landes; 1995. p. 289-330.

[11] Brosius J, Tiedge H. Dendritic BC1 RNA: intracellular transport and activity-dependent modulation. In: Richter D, editor. Cell polarity and subcellular RNA localization. Berlin: Springer-Verlag; 2001. p. 129-38.

[12] Crabbe JC, Wahlsten D, Dudek BC. Genetics of mouse behavior: interactions with laboratory environment. Science 1999;284:1670-2.

[13] Crusio WE. Genetic dissection of mouse exploratory behaviour. Behav Brain Res 2001;125:127-32.

[14] Crusio WE, van Abeelen JH. The genetic architecture of behavioural responses to novelty in mice. Heredity 1986;56:55-63.

[15] DeChiara TM, Brosius J. Neural BC1 RNA: cDNA clones reveal nonrepetitive sequence content. Proc Natl Acad Sci USA 1987;84:26248.

[16] Dell'Omo G, Ricceri L, Wolfer DP, Poletaeva II, Lipp H-P. Temporal and spatial adaptation to food restriction in mice under naturalistic conditions. Behav Brain Res 2000;115:1-8.

[17] Fox WM. Reflex-ontogeny and behavioural development of the mouse. Anim Behav 1965;13:234-41.

[18] Gould SJ, Vbra ES. Exaptation a missing term in the science of form. Paleobiology 1982;8:4-15.

[19] Jacobs LF, Gaulin SJ, Sherry DF, Hoffman GE. Evolution of spatial cognition: sex-specific patterns of spatial behavior predict hippocampal size. Proc Natl Acad Sci USA 1990;87:6349-52.

[20] Kamil AC. A synthetic approach to the study of animal intelligence. In: Leger DW, editor. Comparative perspectives in modern psychol- ogy: Nebraska symposium on motivation, vol. 35. Lincoln: University of Nebraska Press; 1988. p. 230-57.

[21] Kondrashov AV. Common principles of the regulatory systems of transcription and translation as revealed by module structure of preinitiation TATA-complex and BC1 RNA. PhD dissertation, Institute of Cytology. St. Petersburg: Russian Academy of Sciences; 2001.

[22] Kumar S, Hedges SB. A molecular timescale for vertebrate evolution. Nature 1998;392:917-20.

[23] Ledent C, Vaugeois JM, Schiffmann SN, Pedrazzini T, El Yacoubi $\mathrm{M}$, Vanderhaeghen JJ, et al. Aggressiveness hypoalgesia and high blood pressure in mice lacking the adenosine A2a receptor. Nature 1997;388:674-8.

[24] LeDoux JE. Emotion circuits in the brain. Annu Rev Neurosci 2000;23:155-84.

[25] Lewejohann L, Edich I, Sachser N. Circadian rhythm of three closely related inbred strains of mice differing in aggressive behaviour. Zoology 2001;104(Suppl IV, DZG 94.1):7.

[26] Lin Y, Brosius J, Tiedge H. Neuronal BC1 RNA: co-expression with growth-associated protein-43 messenger RNA. Neuroscience 2001;103:465-79.

[27] Lipp H-P, Wolfer DP. Genetically modified mice and cognition. Curr Opin Neurobiol 1998;8:272-80.

[28] Lister RG. The use of a plus-maze to measure anxiety in the mouse. Psychopharmacology 1987;92:180-5.

[29] Marashi V, Barnekow A, Ossendorf E, Sachser N. Effects of different forms of environmental enrichment on behavioral, endocrinological and immunological parameters in male mice. Horm Behav 2003;43:281-92.

[30] Martignetti JA, Brosius J. Neural BC1 RNA as an evolutionary marker: guinea pig remains a rodent. Proc Natl Acad Sci USA 1993;90:9698-702.

[31] Mayr E. Systematics and the origin of species from the viewpoint of a zoologist. New York: Columbia University Press; 1942.

[32] Morris R. Developments of a water-maze procedure for studying spatial learning in the rat. J Neurosci Methods 1984;11:47-60.

[33] Olton DS, Samuelson RJ. Remembrance of places passed: spatial memory in rats. J Exp Psychol Anim Behav Proc 1976;2:97-116.

[34] Olsson AS, Dahlborn K. Improving housing conditions for laboratory mice: a review of 'environmental enrichment'. Lab Anim 2002;36:243-70.

[35] Pellow S, Chopin P, File SE, Briley M. Validation of open: closed arm entries in an elevated plus-maze as a measure of anxiety in the rat. J Neurosci Methods 1985;14:149-67.

[36] Pleskacheva MG, Wolfer DP, Kupriyanova IF, Nikolenko DL, Scheffrahn H, Dell'Omo G, et al. Hippocampal mossy fibers and swimming navigation learning in two vole species occupying different habitats. Hippocampus 2000;10:17-30.

[37] Prior H, Sachser N. Effects of enriched housing environment on the behaviour of young male and female mice in four exploratory tasks. J Exp Anim Sci 1995;37:57-68.

[38] Prior H, Schwegler H, Dücker G. Dissociation of spatial reference memory, spatial working memory, and hippocampal mossy fiber distribution in two rat strains differing in emotionality. Behav Brain Res 1997;87:183-94.

[39] Rice WR. Analyzing tables of statistical tests. Evolution 1989;43:223-5.

[40] Rogers DC, Peters J, Martin JE, Ball S, Nicholson SJ, Witherden AS, et al. SHIRPA a protocol for behavioral assessment: validation for longitudinal study of neurological dysfunction in mice. Neurosci Lett 2001;306:89-92.

[41] Skryabin BV, Sukonina V, Jordan U, Lewejohann L, Sachser N, Muslimov I, et al. Neuronal untranslated BC1 RNA: targeted gene elimination in mice. Mol Cell Biol 2003;23:6435-41.

[42] Stewart M, Fox SE. Do septal neurons pace the hippocampal theta rhythm? Trends Neurosci 1990;13:163-8.

[43] Tiedge H, Bloom FE, Richter D. RNA, whither goest thou? Science 1999;283:186-7. 
[44] Tiedge H, Brosius J. Translational machinery in dendrites of hippocampal neurons in culture. J Neurosci 1996;16:7171-81.

[45] Tiedge H, Fremeau Jr RT, Weinstock PH, Arancio O, Brosius J. Dendritic location of neural BC1 RNA. Proc Natl Acad Sci USA 1991;88:2093-7.

[46] Voikar V, Koks S, Vasar E, Rauvala H. Strain and gender differences in the behavior of mouse lines commonly used in transgenic studies. Physiol Behav 2001;72:271-81.

[47] Walsh RN, Cummins RA. The open-field test: a critical review. Psychol Bull 1976;83:482-504.

[48] Wang H, Iacoangeli A, Popp S, Muslimov IA, Imataka H, Sonenberg N, et al. Dendritic BC1 RNA: functional role in regulation of translation initiation. J Neurosci 2002;22:10232-41.
[49] Welzl H, D’Adamo P, Lipp H-P. Conditioned taste aversion as a learning and memory paradigm. Behav Brain Res 2001;125:205-13.

[50] Wolfer DP, Madani R, Valenti P, Lipp H-P. Extended analysis of path data from mutant mice using the public domain software WINTRACK. Physiol Behav 2001;73:745-53.

[51] Wolfer DP, Muller U, Stagliar M, Lipp H-P. Assessing the effects of the $129 / \mathrm{Sv}$ genetic background on swimming navigation learning in transgenic mutants: a study using mice with a modified beta-amyloid precursor protein gene. Brain Res 1997;771:1-13.

[52] Würbel $\mathrm{H}$. Behaviour and the standardization fallacy. Nat Genet 2000;26:263.

[53] Würbel H. Behavioral phenotyping enhanced-beyond (environmental) standardization. Genes Brain Behav 2002;1:3-8. 